our own review. Just as importantly, quantitative analysis also allows summary conclusions to be reached on the basis of as many cases as possible. It is the number of cases entered in randomised studies that determine the confidence we can have in the findings. An overview of treatment studies in breast cancer illustrates the point $(n=75000)$, and previous controversy over the same treatments exemplifies what may be described as the qualitative fallacy (Early Breast Cancer Trialists' Collaborative Group, 1992). The latter publication shows what can be done when clinicians take treatment issues seriously. We will be delighted if our conclusions serve as a stimulus to further studies on patients defined more strictly for refractory illness. However, the existing data from randomised trials, together with a good deal of more anecdotal evidence which should not be discounted, support the view that lithium augmentation is an effective manoeuvre in patients who have not responded to a tricyclic antidepressant.

Early Breast Cancer Trialists' Collaborative Group (1992) Systemic treatment of early breast cancer by hormonal, cytotoxic, or immune therapy: 133 randomised trials involving 31,000 recurrences and 24,000 deaths among 75,000 women. Lancet, $339,1-15$.

GeORGOTAS, A MCCUE, R. HAPWORTH, W et al (1986) Comparative efficacy and safety of MAOls versus TCAs in treating depression in the elderly. Biological Psychiatry, 21, $1155-1166$.

Hamilton, M. (1960) A rating scale for depression. Journal of Neurology. Neurosurgery and Psychiatry, 23, 56-62.

QuirkIN, F. M., RABKIN, J. G., Ross, D., et al (1984) Duration of antidepressant drug treatment. What is an adequate trial? Archives of General Psychiatry, 41, 238-245.

G. M. GoodwIN

F. G. M. SouzA

MRC Brain Metabolism Unit

Royal Edinburgh Hospital

Morningside Park

Edinburgh EHIO 5HF

Mood Disorders Unit

M.-P. Austin

Prince Henry Hospital

2036 Sydney

Australia

\section{Who benefits from ECT?}

SIR: The casual or unsophisticated reader of the recent article by Buchan et al (Journal, March, 1992, $160,355-359)$, upon encountering the statements in the abstract that "patients who were neither retarded nor deluded did not benefit significantly from real as opposed to simulated ECT", and later in the summary that "real ECT does not appear to be effective in non-retarded, non-deluded patients", might not realise that the authors did not actually determine whether any non-retarded, non-delusional patients were ECT-responders. In fact, Buchan et al have simply demonstrated the truism that removing ECT-responders from a sample of depressives leaves a subsample of ECT non-responders.

Only randomised prospective comparisons of genuine v. sham ECT, with stratification of subjects by the clinical predictor variables of interest (e.g. presence of delusions or retardation), can definitely answer the question: "Who benefits from ECT?".

RICHARD ABRAMS

Department of Psychiatry and Behavioral Sciences 3333 Green Bay Road

North Chicago

Illinois 60064-3095

USA

\section{Do benzodiazepines interfere with the action of ECT?}

SIR: Cohen \& Lawton (Journal, April 1992, 160, 545-546) suggest that the presence of benzodiazepine drugs may interfere with the ability of the brain to respond to bilateral ECT. I would point out that, in experimental animals at least, there is indeed evidence for this.

When electroconvulsive shocks (ECS) are given to mice in a manner somewhat similar to the clinical administration of ECT ( 5 ECS given spread out over 10 days to anaesthetised animals) various changes occur in neurotransmitter function. These include enhanced behavioural responses to drugs stimulating dopamine and 5- $\mathrm{HT}_{2}$ receptors and an attenuated response to the sedative effects of the $\alpha_{2}$ adrenoceptor agonist clonidine (for review see Green \& Nutt, 1987) and it has been proposed that some of these changes could be associated with the antidepressant action of ECT (Green \& Nutt, 1987).

When diazepam was given before each ECS, the dopamine and 5- $\mathrm{HT}_{2}$-receptor-mediated behavioural changes no longer occurred (Green \& Mountford, 1985). This was clearly not due to any modification by the benzodiazepine of the convulsant effect of the ECS both because no obvious modification was seen to occur and, most critically, because the same effect was seen when the diazepam was given 5 minutes after the ECS administration. This effect of diazepam also appeared to be due to a specific action at the benzodiazepine receptor-binding site in the brain because the selective benzodiazepine antagonist flumazenil blocked the effect of diazepam on the ECS-induced changes (Green \& Mountford, 1985).

It is always difficult to speculate on the relevance of animal experimentation to clinical practice. 
Nevertheless, in this instance there does seem to be the possibility that the data reported in our papers have significance to the clinical observation of Cohen \& Lawton.

GREeN, A. R. \& MOUNTFORD, J. A. (1985) Diazepam administration to mice prevents some of the changes in monoamine mediated behaviour produced by repeated electroconvulsive shock treatment. Psychopharmacology, 86, 190-193.

- \& NUTT, D. J. (1987) Psychopharmacology of repeated seizures: possible relevance to the mechanism of action of electroconvulsive therapy. In Handbook of Psychopharmacology (eds L. L. Iversen, S. D. Iversen \& S. H. Snyder), 19, 375-419.

Astra Neuroscience Research Unit

A. RICHARD GREEN

1 Wakefield Street

London WCIN IPJ

\section{Drug therapy of post-traumatic stress disorder}

SIR: We feel concerned that Davidson's comprehensive review of the drug therapy of post-traumatic stress disorder (PTSD) (Journal, March 1992, 160, 309-314) may serve to encourage those unfamiliar with the condition to consider medication as the first line of treatment. The studies reviewed suggest medication may help, but some of the benefits can probably be accounted for by the treatment of a coexisting depressive disorder rather than the treatment of PTSD per se.

Fairbank \& Nicholson (1987) reviewed dynamic, behavioural and biochemical models of treatment and found that direct therapeutic exposure appeared to emerge as the single most important factor in the treatment of PTSD. Richards \& Rose (1991) described rapid, effective therapy with a combination of in vivo and imaginal exposure in four cases of longstanding and severely debilitating PTSD.

We too are experiencing rapid improvement in PTSD sufferers using audiotaped imaginal exposure without concomitant medication, even in those with marked symptoms of hyperarousal.

We agree with Davidson's call for more formal research into the behavioural treatment of PTSD and comparative and interactive studies of it and pharmacotherapy. We also acknowledge that there is a lack of empirical data relating to the treatment of PTSD with exposure therapy. However, with the present body of knowledge and the acceptability of exposure therapy to the patient, we feel it should be used as the first-line treatment in PTSD, with medication being reserved as second line or used to treat a coexisting problem such as depressive disorder.
Fairbank, J. A \& Nicholson, R. A. (1987) Theoretical and empirical issues in the treatment of post-traumatic stress disorder in Vietnam veterans. Journal of Cinical Psychology, 43, 44-55.

Richards, D. A. \& Rose, J. S. (1991) Exposure therapy for posttraumatic stress disorder. Four case studies. British Journal of Psychiatry, 158, 836-840.

JONATHON I. BISSON NORMAN JONES

Department of Psychiatry

\section{$B M H$ Iserlohn}

BFPO 24

\section{Acute transient stress-induced hallucinations in} soldiers

SIR: The most likely explanation of the pseudohallucinations in the three frightened recruits (Journal, March 1992, 160, 414-416) is that they were hypnagogic phenomena. It is a pity that Dr Spivack and his colleagues do not mention this in their discussion which deals exclusively and very well with content but not with form. The thoughts described were no doubt going through the minds of the soldiers, but why in the form of pseudohallucinations?

These phenomena are common in ordinary psychiatric practice. They are often left unexplained or may even lead to an incorrect diagnosis, but if you ask about the circumstances in which they occurred you often find that the patient was sitting alone in a comfortable armchair, perhaps in front of the television, or was in bed, so there is a reasonable presumption that he may briefly have dropped off to sleep. The paper tells us that each patient was alone but does not say in what circumstances although the large ants in case 1 should have given the authors the clue to ask.

The paper refers to similar phenomena in so-called post-traumatic stress disorder (PTSD). Alcohol consumption is high in these patients (Wilson, 1988), which probably accounts for a great deal of their anxiety; the subjects may also be more likely to fall asleep than otherwise or may be experiencing the warning symptoms of delirium tremens.

The "common underlying mechanism" is thus anxiety which accounts both for the anxiety-laden thoughts and for the disruption of the normally smooth process of falling asleep. There may be an additional toxic mechanism if the patient is drinking.

WILSON, G. T. (1988) Alcohol and anxiety. Behaviour Research Therapy, 26, 369-381.

8 Linnell Drive

Samuel I. Cohen 